\title{
The Relationships among Imagination, Future Imagination Tendency, and Future Time Perspective of Junior High School Students
}

\author{
Min-Ying Tsai \\ Department of Special Education at National Taiwan Normal University, Taiwan
}

Copyright (C) 2015 Horizon Research Publishing All rights reserved.

\begin{abstract}
The main purpose of the study were to investigate the relationships among imagination, future imagination tendency, and future time perspective of junior high school students, then to explore the future time perspective which is predicted by background variables, imaginative qualities, and future imagination tendency. The subjects were 331 from the junior high school in Kaohsiung City. The main research tool is the Imagination Questionnaire, the Future imagination tendency Scale, and the Future Time Perspective Scale. The data collected was analyzed by SPSS 18.0 with descriptive statistical analysis, Pearson product-moment correlation coefficient, and multiple stepwise regression procedure. The findings of the study were follows: 1 . It showed a high positive correlation between imagination and future imagination tendency. 2. It showed a middle positive correlation between imagination and future time perspective. 3 . It showed a middle positive correlation between future imagination tendency and future time perspective. 4. Monthly exam results, socioeconomic status, beyond reality, past review and future prediction, emotion and value and plot construction could significantly predict future time perspective. According to the research findings, the researcher gave some suggestions for future implementations.
\end{abstract}

Keywords Imagination, Future Imagination Tendency and Future Time Perspective

\section{Introduction}

Husman and Shell (10) pointed that future time perspective regulates behavior, establishes goals and expectations, motivates and monitors performance on different tasks, and evaluates whether the performance fulfilled the goals. Future time perspective takes a step beyond the sole act of thinking about the future by examining the degree to which one places importance on goals and the degree to which one's present behavior connects to future goals. (22) Simons, Vansteenkiste, Lens, and Lacante (19) noted that future-oriented individuals typically have a better understanding of how their current behavior serves a direct role in attaining those future goals. (cited in 22) Husman and Shell (10) suggested that valuing the future is one indicator that individuals are oriented to the future. (cited in 22) According to DeVolder and Lens (8), present tasks or responsibilities students have are also important components of future time perspective because they lead directly to future goals. In addition, other researchers in the field of educational psychology (8) have used this reasoning and have predicted that students who understand the value of future goals (i.e. valence) would be more motivated to carry out their present tasks, put more effort into them, and perform better on subsequent tests. In evaluating the relationship between valence and instrumentality and motivation, DeVolder and Lens (8) found that more motivated high school students attached more value to goals in the distant future and attached more instrumental value to their schoolwork as a means to reach those goals than less motivated students. Future time perspective apparently has a large effect on career development. If people have a good future time perspective, they can make sure their future goals, plan their future lives, and understand the effect of present efforts on future achievement.

An adolescent's conceptualization of his or her future and the development of this occupational self-concept provide the basis for occupational exploration and the formulation of future plans (2). Dudai and Carruthers (2005) pointed that people would imagine or simulate what happens in the future through the past experiences (1, Lin, E., 2012). People will project themselves to the future imagination which is based on the past experiences. However, future imagination doesn't directly replicate the past experiences. The degree to which one is focused on future-oriented goals is strongly dependent on the degree to which she values the present steps to achieve those goals. The hypothesis of structure plot imitation was to flexibility combine the details of past experiences to imitate the future plots. The past experiences memory were the useful information for future imagination 
(1, Lin, E., 2012). If people would like to establish possible career plans, they would imagine their future life image, find their future goals, and make up the plan to achieve it. So it's important to develop students' imagination properties, and cultivate their future imagination tendency. The research would like to explore the relationship among imagination, future imagination tendency, and future time perspective.

There appear to be two different streams that students may gravitate toward when making a decision about their future: vocational or educational which depends on their socioeconomic backgrounds (2). Some age groups (e.g., older students) were less likely to plan on postsecondary education could be explained by a number of factors - socioeconomic status (11), gender role stereotyping (15), and/or differential education (21). Early family experiences have been found to be highly influential on students' occupational decision making (16), as have perceptions of gender roles (15). Kracke (12) investigated the influence of parental education and behaviors on adolescent career exploration in ninth-grade students in German middle-track schools and found that parental education had a marginal effect on adolescents' career exploration. The research would like to predict students' future time perspective through background variables, imagination properties, and future imagination tendency. There were three research purposes. Firstly, it was to present the current states of imagination properties, future imagination disposition, and future time perspective of junior high school students. Secondly, it was to explore the relationships among imagination, future imagination tendency, and future time perspective of junior high school students. Lastly, it was to test that future time perspective variables were predicted by background variables, imagination properties variables, and future imagination disposition.

\section{Literature Review}

Singer (1999) pointed that imagination was a kind of particular thinking style (cited in 17). People displayed the original imaginative ability from the basic senses, and reflected on the individuals' memory, fantasy, and the conscious of their future plans. These imagines would be reshaped and recombined into the new images or future products, such as creative science, art, or future social interaction. Vygotsky (20) pointed that there are two imaginative behaviors: One is the reproduction of individuals' past experiences, and the other is the imagination ability which originated from people's using and connecting their memory or experiences. Mckellar (1957) divided imagination into memory images and imagination images: The former meant that the extraction of the present memory which is formed by individuals' learning and experiences in their daily lives and the latter meant that creation and imagination of nonexistent images $(6,17)$. Thinking about the future was expanded one's imagination to the future, and he could imagine the future based on the past experiences to plan their future, or based on creativity to build new prospect. If imagination was connected to the future, it could be supposed that memory images belonged to future time perspective, and imagination images belonged to future imagination tendency.

According to the pattern of mental operation, and time property of imagined goals, imagination includes three parts: reproductive imagination, creative imagination, and predictive imagination. (6) Zhang (27) thought that reproductive imagination was the reorganization of past experiences and reproduce in our memory. Reproductive imagination is related to the memory of the past experiences which is abstracted from the brain. Zhang (27) pointed that creative thinking was that people consciously reorganized the past experiences, and attempted to transcend the past experiences to produce new constructs. Those new constructs belonged to non-existing knowledge area beyond the temporal constrains. Imagination is a possible and non-factual thinking which think about what the things might be, not what the present facts ought to be (White, 1990; cited in 17). Barrow (3) indicated that imagination is the ability to imagine unusual things. In short, imagination is a construct of beyond reality and pre-existing knowledge which belongs to the construct of creative imagination. Wu (24) indicated that the definition of future imagination tendency was that individuals have intended to attend the future thinking activities, and were accustomed to systematically and critically think about the cause-effect speculation, and construct possible future plots. Because future is unpredicted, people could imagine the trends and development of the future, and prepare in advance. $\mathrm{Wu}$, Chang, Chen, and Chiu (25) concluded that future imagination tendency included positive feeling, beyond reality, cause-effect speculation, and vision construction through literature review and factor analysis. Chen (6) indicated that future imagination is a kind of imagination activities through the future time contexts, including creative imagination and predictive imagination, and also the future thinking process which is based on imagination. Apparently, people with future imagination tendency depended on their imagination. Future imagination tendency is closely connected with the imagination.

In terms of futurology, individuals who think about the future belonged to the thinking style with time. (24) Wallace (1956) defined the extension of future time perspective (FTP) as "the length of the future time span which is conceptualized. Future time perspective has been conceptually understood as the individual mental representation of the future, and defined as an individual's ability to move into the past through the use of memory and/or to imagine the future. (14, 22) Future time perspective concept describes how much time individuals believe they have left in their future and how they perceive that time (5). Future time perspective has to be distinguished from trait-like concepts, for example, Zimbardo's “future orientation" (28) and Bluedorn's concept 
of "temporal depth", which refer to stable modes of thought and behavior. (cited in 26) In contrast, future time perspective as conceptualized by Carstensen (4) and Cate and John (5) are a flexible, cognitive-motivational, and age-related construct that changes over time. Carstensen (4) conceived future time perspective as a one-dimensional temporal construct, ranging from expansive to limited time left. Savickas, Silling, and Schwartz (18) posit that people's ability to think in terms of time perspective -looking beyond immediate tasks and obstacles- is a good indicator of level of career indecision.

Recently, Cate and John (5) showed that future time perspective can also be conceived in terms of two qualitative dimensions: Focus on opportunities and focus on limitations. Individuals with a strong focus on opportunities perceive their futures in positive ways. They concentrate on the options, plans, and goals, they can still pursue in their remaining life time. In contrast, individuals with a strong focus on limitations perceive many restrictions and boundaries that lie in the time ahead, and concentrate on losses and limitations. Simons et al. (19) argued that there is a strong relationship between future time perspective and the utility of what the person is doing. That is, individuals with longer future time perspective perceive their present behavior as more instrumental in achieving a broad range of short-term and long-term goals. If people who look on the bright side on the future, they would set up their future goals, and try their best to achieve them. If they had the positive imagination to the future lives, they would have better future imagination tendency, and future time perspective. Future time perspective is closely related to the imagination.

Early studies reviewed by Green and Debacker supported the stereotypical belief that women and men differed in their academic motivation and life expectations. (cited in 22) Women tended to be less competitive about their future ambitions and present tasks associated with those ambitions. (cited in 22) Recent research reveals that men report more hopes and fears about the future in the career domain, whereas women report more socially oriented hopes and fears into the future. (cited in 22) Potential reasons for such discrepancies have included age, parenting styles, socioeconomic status, culture, and societal beliefs about raising children. (cited in 22) In this article, the study further explore whether background variables, imagination property, and future imagination tendency could significantly predict future time perspective.

\section{Research Method}

\section{Participants}

Participants were 158 girls and 153 boys from one school in Kaohsiung, Taiwan. A total of 311 individuals took part, of whom 67 were seventh grade students, 134 eighth grade students and 110 ninth grade students.

\section{Measures and Procedure}

There were four parts of each questionnaire. The first part was demographic information. The second part included the imagination questionnaire, the scale of future imagination tendency, and the future time perspective scale. Participants were asked to rate themselves and write their demographic information in class over a period of approximately 45 minutes.

\section{The imagination questionnaire}

The imagination questionnaire includes positive feeling, future imagination, problem solving, and clear imagination (Lin, Zhu, Wang, Zhu, \& Liu, 2011). The instrument consists of 11 items on a Likert-scale from 1 (totally disagree) to 6 (totally agree). The internal consistency reliability ( $\alpha$ coefficient) are .61 .88. The correlation coefficient for each subscale interaction are $.35 \sim .77$. In terms of construct validity, the four factors explain $59.57 \%$ of the total variance.

\section{The future time perspective scale}

The future time perspective scale includes four subscales: discussion of future goals, the importance of perceived future goals, the connection of future goals, and the preparation of future goals (9). The instrument consists of 20 items on a Likert-scale from 1 (totally disagree) to 4 (totally agree). The internal consistency reliability ( $\alpha$ coefficient) are $.61 \sim .88$. The correlation coefficient for each subscale interaction are $.77 \sim .86$. The re-test correlation coefficient are $.59 \sim .64$. In terms of construct validity, the four factors explain $61.30 \%$ of the total variance, and factor loadings of all items are above .45 .

\section{The future imagination tendency scale}

The future imagination tendency scale measures four dimensions: beyond reality, past review and future prediction, emotion and value, and plot construction. (24) The instrument consists of 20 items on a Likert-scale from 1 (totally disagree) to 6 (totally agree). The internal consistency reliability ( $\alpha$ coefficient) are $.61 \sim .88$. The correlation coefficient for each subscale interaction are $.83 \sim .86$. The re-test correlation coefficient are $.61 \sim .77$. In terms of construct validity, the four factors explain $57.2 \%$ of the total variance.

\section{Demographic information}

Participants provided some demographic information, including gender, age, parenting style, birth order, first exam results, and father and mother socioeconomic status.

\section{Data analysis}

SPSS 18.00 was used to analyze the data collected for the study. Simple descriptive statistics were attained to identify the state of imagination property, future imagination tendency, and future time perspective. Pearson correlation 
was used to analysis the relationship among the imagination property, future imagination tendency, and future time perspective scale. In order to investigate the prediction among background variables, imagination property, and future imagination tendency on students' future time perspective, the data were analyzed inferentially by hierarchical regression analysis.

\section{Results}

Description statistics of imagination, future imagination tendency, and future time perspective

In Table1, the mean of each item in future imagination tendency subscales and total scores were between $3 \sim 4$. It showed that most students had little tended to the future imagination tendency. The mean of each item in future time perspective subscales and total scores were between $2 \sim 3$. It showed that most students had little tended to the future time perspective. The mean of each item in imagination subscales and total scores were 4. It showed that most students had tended to imagination. From three tests, it indicated that most student respondents had tended to middle-digit option.

\section{Relationship between Future Imagination Tendency and Imagination Property}

In Table 2, the correlation coefficient between the various variables of future imagination tendency and imagination of junior high school students were $.540 \sim .873$. The various variables of future imagination tendency were positively correlated to those of imagination property. Beyond reality, past review and future prediction, and plot construction subscales were little highly correlated to the imagination subscales and total scale. Past review and future prediction, and future imagination tendency total scale were strongly correlated to the imagination subscales and total scale. It showed that when student's imagination were more remarkable, their future imagination tendency were higher.

Table 1. Description statistics of imagination, future imagination tendency, and future time perspective

\begin{tabular}{|c|c|c|c|c|c|c|}
\hline test & item & means & SD & $\mathrm{N}$ & Item number & Means of each item \\
\hline \multirow{5}{*}{$\begin{array}{l}\text { future imagination } \\
\text { tendency }\end{array}$} & beyond reality & 19.77 & 7.019 & 308 & 5 & 3.95 \\
\hline & past review and future prediction & 20.60 & 5.12 & 306 & 5 & 4.12 \\
\hline & emotion and value & 20.64 & 5.75 & 299 & 5 & 4.13 \\
\hline & plot construction & 18.68 & 6.89 & 305 & 5 & 3.74 \\
\hline & total & 79.83 & 20.68 & 288 & 20 & 3.99 \\
\hline \multirow{5}{*}{ future time perspective } & the discussion of future goals & 13.96 & 3.07 & 303 & 5 & 2.79 \\
\hline & $\begin{array}{l}\text { the importance of perceived } \\
\text { future goals }\end{array}$ & 15.35 & 2.79 & 303 & 5 & 3.07 \\
\hline & the connection of future goals & 14.75 & 2.73 & 306 & 5 & 2.95 \\
\hline & the preparation of future goals & 14.13 & 2.80 & 309 & 5 & 2.83 \\
\hline & total & 58.26 & 10.11 & 294 & 20 & 2.91 \\
\hline \multirow{5}{*}{ imagination } & positive feeling & 12.80 & 3.95 & 308 & 3 & 4.27 \\
\hline & future imagination & 12.81 & 3.84 & 308 & 3 & 4.27 \\
\hline & problem solving & 12.27 & 3.71 & 308 & 3 & 4.09 \\
\hline & clear imagination & 8.14 & 2.78 & 309 & 2 & 4.07 \\
\hline & total & 45.95 & 12.86 & 300 & 11 & 4.18 \\
\hline
\end{tabular}

Table 2. Correlation matrix of imagination, and future imagination tendency

\begin{tabular}{|c|c|c|c|c|c|}
\hline correlation coefficient & beyond reality & $\begin{array}{c}\text { past review and future } \\
\text { prediction }\end{array}$ & $\begin{array}{c}\text { emotion and } \\
\text { value }\end{array}$ & plot construction & total \\
\hline positive feeling & $.620^{* *}$ & $.635^{* *}$ & $.759^{* *}$ & $.654^{* *}$ & $.811^{* *}$ \\
\hline future imagination & $.540^{* *}$ & $.578^{* *}$ & $.746^{* *}$ & $.695^{* *}$ & $.787^{* *}$ \\
\hline problem solving & $.546^{* *}$ & $.736^{* *}$ & $.719^{* *}$ & $.632^{* *}$ & $.795^{* *}$ \\
\hline clear imagination & $.549^{* *}$ & $.627^{* *}$ & $.675^{* *}$ & $.556^{* *}$ & $.721^{* *}$ \\
\hline total & $.636^{* *}$ & $.722^{* *}$ & $.815^{* *}$ & $.723^{* *}$ & $.873^{* *}$ \\
\hline
\end{tabular}

$* * p<.01$ 
Table 3. Correlation matrix of future imagination tendency, and future time perspective

\begin{tabular}{|c|c|c|c|c|c|}
\hline correlation coefficient & beyond reality & past review and future prediction & emotion and value & plot construction & total \\
\hline the discussion of future goals & $.139^{*}$ & $.485^{* *}$ & $.453^{* *}$ & $.234^{* *}$ & $.392^{* *}$ \\
\hline the importance of perceived future goals & $.139^{*}$ & $.606^{* *}$ & $.533^{* *}$ & $.285^{* *}$ & $.457^{* *}$ \\
\hline the connection of future goals & $.147^{*}$ & $.643^{* *}$ & $.522^{* *}$ & $.264^{* *}$ & $.469^{* *}$ \\
\hline the preparation of future goals & $.141^{*}$ & $.611^{* *}$ & $.477^{* *}$ & $.275^{* *}$ & $.453^{* *}$ \\
\hline total & $.167^{* *}$ & $.659^{* *}$ & $.553^{* *}$ & $.292^{* *}$ & $.494^{* *}$ \\
\hline
\end{tabular}

$* p<.05 \quad * * p<.01$

Table 4. Correlation matrix of imagination, and future time perspective

\begin{tabular}{|c|c|c|c|c|c|}
\hline correlation coefficient & positive feeling & future imagination & problem solving & clear imagination & total \\
\hline the discussion of future goals & $.358^{* *}$ & $.386^{* *}$ & $.344^{* *}$ & $.270^{* *}$ & $.391^{* *}$ \\
\hline the importance of perceived future goals & $.407^{* *}$ & $.424^{* *}$ & $.401^{* *}$ & $.371^{* *}$ & $.445^{* *}$ \\
\hline the connection of future goals & $.419^{* *}$ & $.391^{* *}$ & $.454^{* *}$ & $.372^{* *}$ & $.453^{* *}$ \\
\hline the preparation of future goals & $.368^{* *}$ & $.367^{* *}$ & $.444^{* *}$ & $.367^{* *}$ & $.428^{* *}$ \\
\hline total & $.422^{* *}$ & $.432^{* *}$ & $.449^{* *}$ & $.372^{* *}$ & $.471^{* *}$ \\
\hline
\end{tabular}

$* * p<.01$

Table 5. Hierarchical regression analysis summary of background variables, imagination, future imagination tendency, and future time perspective

\begin{tabular}{|c|c|c|c|c|c|c|c|c|c|c|c|}
\hline \multirow{2}{*}{$\begin{array}{l}\text { hierarchical } \\
\text { variables }\end{array}$} & \multirow{2}{*}{$\begin{array}{l}\text { predicted } \\
\text { variables }\end{array}$} & \multicolumn{2}{|c|}{ total } & \multicolumn{2}{|c|}{$\begin{array}{l}\text { the discussion of } \\
\text { future goals }\end{array}$} & \multicolumn{2}{|c|}{$\begin{array}{l}\text { the importance of } \\
\text { perceived future goals }\end{array}$} & \multicolumn{2}{|c|}{$\begin{array}{l}\text { the connection of } \\
\text { future goals }\end{array}$} & \multicolumn{2}{|c|}{$\begin{array}{l}\text { the preparation of } \\
\text { future goals }\end{array}$} \\
\hline & & $\begin{array}{c}\text { model } \\
1\end{array}$ & $\begin{array}{c}\text { Model } \\
2\end{array}$ & model1 & Model2 & model1 & Model2 & model1 & $\begin{array}{c}\text { Model } \\
2\end{array}$ & model1 & $\begin{array}{c}\text { Model } \\
2\end{array}$ \\
\hline \multirow{6}{*}{$\begin{array}{l}\text { background } \\
\text { variables }\end{array}$} & grade & $\begin{array}{c}-.148 \\
*\end{array}$ & -.081 & -.098 & -.069 & -.106 & -.059 & $-.162 *$ & -.097 & -.123 & -.071 \\
\hline & gender & .034 & .062 & .018 & .026 & .056 & .084 & .028 & .057 & .008 & .066 \\
\hline & birth order & -.045 & .047 & -.017 & .044 & -.075 & .023 & -.027 & .067. & -.091 & .002 \\
\hline & $\begin{array}{l}\text { first exam } \\
\text { results }\end{array}$ & $.178^{*}$ & .079 & .039 & -.039 & $.202 * *$ & .104 & $.264 * * *$ & $.163 * *$ & $.169^{*}$ & .057 \\
\hline & $\begin{array}{c}\text { father } \\
\text { socioeconomi } \\
\text { c status }\end{array}$ & .146 & $.163^{*}$ & $.190^{*}$ & $.209 * *$ & .151 & $.182 * *$ & .103 & $.127^{*}$ & .043 & .063 \\
\hline & $\begin{array}{c}\text { mother } \\
\text { socioeconomi } \\
\text { c status }\end{array}$ & -.129 & $-.131^{*}$ & -.146 & -.143 & -.128 & $-.146^{*}$ & -.141 & $-.152 *$ & -.031 & -.039 \\
\hline \multirow{4}{*}{ imagination } & $\begin{array}{c}\text { positive } \\
\text { feeling }\end{array}$ & & -.004 & & .120 & & -.011 & & .045 & & -.117 \\
\hline & $\begin{array}{c}\text { future } \\
\text { imagination }\end{array}$ & & .177 & & .230 & & .146 & & .076 & & .061 \\
\hline & $\begin{array}{c}\text { problem } \\
\text { solving }\end{array}$ & & -.095 & & -.123 & & -.119 & & -.024 & & -.046 \\
\hline & $\begin{array}{c}\text { clear } \\
\text { imagination }\end{array}$ & & -.108 & & -.177 & & -.045 & & -.102 & & .035 \\
\hline \multirow{4}{*}{$\begin{array}{c}\text { future } \\
\text { imagination } \\
\text { tendency }\end{array}$} & $\begin{array}{l}\text { beyond } \\
\text { reality }\end{array}$ & & $-.161^{*}$ & & -.086 & & $-.221 * *$ & & $\begin{array}{c}-.217 * \\
*\end{array}$ & & -.142 \\
\hline & $\begin{array}{l}\text { past review } \\
\text { and future } \\
\text { prediction }\end{array}$ & & $\begin{array}{c}.614 * * \\
*\end{array}$ & & $.411^{* * *}$ & & $.499 * * *$ & & $\begin{array}{l}.600 * * \\
*\end{array}$ & & $\begin{array}{l}.578^{* *} \\
*\end{array}$ \\
\hline & $\begin{array}{c}\text { emotion and } \\
\text { value }\end{array}$ & & $.307 * *$ & & $.269 *$ & & $.406^{* * *}$ & & $.272 * *$ & & $.219 *$ \\
\hline & $\begin{array}{c}\text { plot } \\
\text { construction }\end{array}$ & & -.098 & & -.122 & & -.069 & & -.072 & & -.012 \\
\hline \multirow{4}{*}{ summary } & $R^{2}$ & .078 & .558 & .038 & .355 & .084 & .528 & .114 & .553 & .058 & .435 \\
\hline & $\mathrm{F}$ 值 & $\begin{array}{c}2.673 \\
*\end{array}$ & $\begin{array}{c}16.292 \\
* * *\end{array}$ & 1.275 & $7.273^{* * *}$ & $2.931 * *$ & $\begin{array}{c}14.714 * * \\
*\end{array}$ & $4.126^{* *}$ & $\begin{array}{c}16.290 \\
* * *\end{array}$ & 1.973 & 10.222 \\
\hline & $\Delta R^{2}$ & .078 & .479 & .038 & .317 & .084 & .444 & .114 & .439 & .058 & .377 \\
\hline & $\Delta \mathrm{F}$ 值 & $\begin{array}{c}2.673 \\
*\end{array}$ & $\begin{array}{c}24.512 \\
* * *\end{array}$ & 1.275 & $\begin{array}{c}11.360 * * \\
*\end{array}$ & $2.931 * *$ & $\begin{array}{c}21.660 * * \\
*\end{array}$ & $4.126^{* *}$ & $\begin{array}{c}22.625 \\
* * *\end{array}$ & 1.973 & $\begin{array}{c}15.524 \\
* * *\end{array}$ \\
\hline
\end{tabular}

$*<.05 \quad * * .01 \quad * * * .001$ 


\section{Relationship between future imagination tendency and future time perspective}

In Table 3, the correlation coefficient between the various variables of future imagination tendency and future time perspective of junior high school students were .139 .659. The various variables of future imagination tendency were positively correlated to those of future time perspective. Beyond reality, and plot construction subscales were low correlation with the future time perspective subscales and total scale. Emotion and value, and future imagination tendency total scale were middle correlation with the future time perspective subscales and total scale. Past review and future prediction subscale little highly correlated to the future time perspective subscales and total scale. It showed that when student have more future imagination tendency, their future time perspective were higher.

\section{Relationship between imagination, and future time perspective}

In Table 4, the correlation coefficient between the various variables of imagination and future time perspective of junior high school students were $.270 \sim .454$. The various variables of imagination were positively correlated to those of future time perspective. Clear imagination subscale was middle correlation with the future time perspective subscales and total scale. Positive feeling, future imagination, problem solving subscales, and imagination total scale were middle correlation with the future time perspective subscales and total scale. It showed that when student's imagination were more remarkable, their future time perspective were higher.

\section{Background variables, imagination, and future imagination tendency predicted future time perspective}

The study use hierarchical regression analysis to analysis the data, there were two levels as follows: The first level was background variables, and the second level included imagination, and future imagination tendency. In Table 5, The first level of background variables could independently explain $3.8 \% \sim 11.4 \%$ of the variance of future time perspective. It showed that background variables had lower explanatory power for the dependent variable. The second level of imagination, and future imagination tendency variables could independently explain $35.5 \% \sim 55.8 \%$ of the variance of future time perspective. It showed that imagination, and future imagination tendency variables had middle explanatory power for the dependent variable.

In the regression of first model, the beta coefficient of grade and first exam results variables to total scores were -.148 $(t=-2.103, p=.037)$, and $.178(t=2.487, p=.014)$. The beta coefficient of father socioeconomic status variable to the discussion of future goals variable was $.190 \quad(t=2.191$, $p=.030$ ). The beta coefficient of the first exam results variable to the importance of perceived future goals variable was .202 ( $t=2.849, p=.005)$. The beta coefficient of grade and first exam results variables to the connection of future goals variable were $-.162(t=-2.368, p=.019<.05)$, and .264 $(t=3.781, p=.000<.001)$. The results indicated that younger students had better future time perspective and the connection of future goals. Students got higher scores in first exam, and their future time perspective, the importance of perceived future goals, the connection of future goals, and the importance of perceived future goals were better. Students with higher father socioeconomic status got higher scores on the discussion of future goals variable.

Daltrey and Lenger (1984) found that grade variable was negative lower correlation with the extension and coherence of future time perspective (cited in 7). Geern and DeBacker (2004) reported that boys and girls in puberty have similar expectations of life lessons (cited in 7). Girls had more varied and complicated life goals, and more expectations and fears in social life. Boys had far extension than girls, and more expectations and fears in their career. Husman, McCann, and Crowson (2000) concluded that future time perspective was related to the students' achievement; Nussin and Lens (1985) found that academic grade, achievement motivation, and future time perspective were positively correlated (cited in 7). The results of model one were consistent with the results of Daltrey and Lenger (1984), Husman, McCann, and Crowson (2000), and Nussin and Lens (1985), but not consistent with the results of Geern and DeBacker (2004).

In the regression of second model, the beta coefficient of father and mother socioeconomic status, beyond reality, past review and future prediction, and emotion and value variables to total scores variable were $.163(t=2.613$, $p=.010), \quad-.131 \quad(t=-2.101, \quad p=.037), \quad-.161 \quad(t=-2.232$, $p=.027), .614(t=6.774, p=.000)$, and $.307(t=3.192, p=.002)$. The beta coefficient of father socioeconomic status, past review and future prediction, and emotion and value variables to the discussion of future goals variable were .209 $(t=2.824, p=.005), .411 \quad(t=3.850, \quad p=.000)$, and .269 $(t=2.319, p=.021)$. The beta coefficient of father and mother socioeconomic status, beyond reality, past review and future prediction, and emotion and value variables to the importance of perceived future goals were $.182(t=2.866$, $p=.005), \quad-.146 \quad(t=-2.296, \quad p=.023), \quad-221 \quad(t=-3.033$, $p=.003), .499(t=5.388, p=.000)$, and $.406(t=4.173, p=.000)$. The beta coefficient of first exam results, father and mother socioeconomic status, beyond reality, past review and future prediction, and emotion and value variables to the connection of future goals were $.163(t=3.150, p=.002), .127$ $(t=2.057, p=.041),-.152(t=-2.457, p=.015),-.217(t=-3.077$, $p=.002), .600(t=6.819, p=.000)$, and $.272(t=2.874, p=.005)$. The beta coefficient of past review and future prediction, and emotion and value variables to the preparation of future goals were $.578(t=5.845, p=.000)$, and $.219(t=2.057$, $p=.041)$. The results reported that students with lower mother socioeconomic status had better future time perspective, the importance of perceived future goals, and the connection of future goals. Students with higher father socioeconomic status had better future time perspective, the 
discussion of future goals, the importance of perceived future goals, and the connection of future goals. Students who got higher scores in first exam only had better the connection of future goals. Students who got lower scores on beyond reality variable had better future time perspective, the importance of perceived future goals, and the connection of future goals. Students who got higher scores on past review and future prediction, and emotion and value variables had better future time perspective subscales and total scores. Without taking imagination, and future imagination tendency variables into consideration, grade and first exam results variables could significantly predict future time perspective. If both considering background variables, imagination, and future imagination tendency variables, grade and first exam results variables had little effect on future time perspective.

Lessing (1968) indicated that people with high socioeconomic status had longer and structured future time perspective than those with low socioeconomic status (cited in 7). Lomranz, Shmotki, and Katznelson (1983) also founded that people with middle socioeconomic status had more coherence of future time perspective, and higher delayed content ability than those with low socioeconomic status (cited in 7). The results found that students with higher father socioeconomic status, and lower mother socioeconomic status had effect on their future time perspective. It was consistent with the results of Lessing (1968), and Lomranz, Shmotki, and Katznelson (1983). The reason of the effect of lower mother socioeconomic status was that some mothers might be housekeepers who had more time to discuss future plans with their children, but the housekeeper style was classed into low socioeconomic status. So mother socioeconomic status variable was significantly negatively to future time perspective.

The results pointed that beyond reality variable was significantly negatively to future time perspective, for beyond reality tended to divergent thinking. Lai (13) pointed that when people imagined the development of future world, all imagination had a common goal to find the best future life to improve human's life. It showed that future time perspective belonged to convergent thinking. Chen (6) indicated that people with future time perspective have the motivation, insistent and value of future goals, seek to existed cues to associate and refer to the possible things in the future, and expect to take actions to achieve future goals and obtain positive feelings. It showed that people who have better past review and future prediction, and emotion and value variables. The results found that students who got higher scores on past review and future prediction, and emotion and value variables had better future time perspective which is quite consistent with the literature.

The limitation of the study was that the study only selected one school to investigate the imagination, future imagination tendency, and future time perspective of junior high school students the sample. In the future, the researchers can expand the sampling range to investigate the different student types, different school or different areas, use structural equation modeland to test the relationship among imagination, future imagination tendency, and future time perspective or explore different variables, such as career planning, creativity.

\section{REFERENCES}

[1] Bai MG, Lin E. Memory of the past, and imagination of the future. Science development. 2012; 475: 38-43,

[2] Bardick AD, Bernes KB, Magnusson KC, Witko KD. Junior High School Students' Career Plans for the Future: A Canadian Perspective. J CAREER DEV, 2012; 32(3): 250-271.

[3] Barrow R. Some observations on the concept of imagination. In: Egan K, Nadaner D, Edtors. Imagination and education. New York(NY): Teachers College Press; 1988. P. 79-90.

[4] Carstensen LL. The influence of a sense of time on human development. Science. 2006; 312: 1913-1915.

[5] Cate RA, John OP. Testing models of the structure and development of future time perspective: Maintaining a focus on opportunities in middle age. Psychol Aging, 2007; 22, 186-201.

[6] Chen YH. The curriculum design and effect evaluation of "Nurturing future imagination and creative talent" of teacher empowerment workshop - A case of high school [master's thesis]. [Taipei (R.O.C.)]: National Taiwan Normal University; 2011. Available from http://ndltd.ncl.edu.tw/cgi-bin/gs32/gsweb.cgi/login?o=dnclc $\mathrm{dr} \& \mathrm{~s}=\mathrm{id}=\% 22100 \mathrm{NTNU} 5808024 \% 22 . \&$ searchmode $=$ basic

[7] Chiu YH. The study of future time perspective for junior high school students [master's thesis]. [Changhua (R.O.C.)]: National Changhua University of Education; 2006. Available from

http://ndltd.ncl.edu.tw/cgi-bin/gs32/gsweb.cgi/login?o=dnclc $\mathrm{dr} \& \mathrm{~s}=\mathrm{id}=\% 22095$ NCUE $5464009 \% 22 . \&$ searchmode $=$ basic

[8] DeVolder ML, Lens W. Academic achievement and future time perspective as a cognitive-motivational concept. J PERS SOC PSYCHOL, 1982; 42, 566-571.

[9] He, J. X. Research on the future time perspective, social support of learning resources, motivation, and academic achievement of junior high school students [master's thesis]. [Taipei (R.O.C.)]: National Taiwan Normal University; 2011. Available from

http://ndltd.ncl.edu.tw/cgi-bin/gs32/gsweb.cgi/login?o=dnclc $\mathrm{dr} \& \mathrm{~s}=\mathrm{id}=\% 22100 \mathrm{NTNU} 5328004 \% 22 . \&$ searchmode $=$ basic

[10] Husman J, Shell DF. Beliefs and perceptions about the future: A measurement of future time perspective. LEARN INDIVID DIFFER, 2008; 18, 166-175.

[11] Klaczynski PA, Laupple JS, Jurden FH. Educational context differences impractical problem solving during adolescence. MERRILL PALMER QUART, 1992; 38, 417-438.

[12] Kracke B. Parental behaviors and adolescents' career exploration. CAREER DEV Q, 1997; 45, 341-350.

[13] Lai MC. An Action Research on Developing the Instructional Program for Future Imagination about the "Myself in 2030" 
[master's thesis]. [Taipei (R.O.C.)]: National Taipei

University of Education; 2011. from

http://www.airitilibrary.com/Publication/alDetailedMesh?do cid $=\mathrm{U} 0055-2607201109482300$

[14] Leondari A. Future time perspective, possible selves, and academic achievement. New dir. adult contin. educ., 2007; $114,17-26$.

[15] Meinster MO, Rose KC. Longitudinal influences of educational aspirations and romantic relationships on adolescent women's vocational interests. J Vocat Behav, $2001 ; 58,313-327$

[16] Mortimer JT, Zimmer-Gembeck MJ, Holmes M. The process of occupational decision making: Patterns during the transition to adulthood. J Vocat Behav, 2002; 61, 439-465.

[17] Qiu FZ, Chen Z, Lin YN, Tu, LP. Preliminary construct of the imagination. J EDUC PSYCHOL, 2012; 44(2), 389-410.

[18] Savickas ML, Silling SM, Schwartz S. Time perspective in vocational maturity and career decision making. Journal of Vocational Behavior, 1984; 25, 258-269.

[19] Simons J, Vansteenkiste M, Lens W, Lacante M. Placing motivation and future time perspective theory in a temporal perspective. EDUC PSYCHOL REV, 2004; 16, 121-139.

[20] Vygotsky LS. Imagination and creativity in childhood. Journal of Russian and East European Psychology, 2004; 42(1), 7-97.
[21] Wahl KH, Blackhurst A. Factors affecting the occupational and educational aspirations of children and adolescents. Professional School Counseling, 2000; 3, 367-374.

[22] Walker TL, Tracey TJG. The role of future time perspective in career decision-making. J Vocat Behav, 2012; 81, $150-158$.

[23] Wallace M. Future time perspective in schizophrenia. J ABNORM SOC PSYCH, 1956; 52, 240-245.

[24] Wu IC. (2011). Developing the scale of future imagination tendency [master's thesis]. [Taipei (R.O.C.)]: National Taiwan Normal University; 2011. Available from http://ndltd.ncl.edu.tw/cgi-bin/gs32/gsweb.cgi/login?o=dnclc $\mathrm{dr} \& \mathrm{~s}=\mathrm{id}=\% 22100 \mathrm{NTNU} 5808017 \% 22 . \&$ searchmode $=$ basic

[25] Wu IC, Chang YL, Chen HC, Chiu FC. Nurture of Futures Imagination and Creative Talent in Senior High School. Journal of Chinese Creativity, 2013; 4(2), 57-78.

[26] Zacher H, Frese M. Remaining time and opportunities at work: Relationships between age, work characteristics, and occupational future time perspective. Psychology and Aging, $2009 ; 24,487-493$.

[27] Zhang CX. Zhang psychology dictionary. Taipei: Donghua Press; 1989.

[28] Zimbardo PG, Boyd JN. Putting time in perspective: A valid, reliable individual-differences metric. J PERS SOC PSYCHOL, 1999; 77(6), 1271-1288. 